\title{
Review on Chemistry, Pharmacology and Toxicity of Paracetamol
}

\author{
Maha A. Hilal $^{1}$, Reda M. Elsayed ${ }^{1}$, Sheren F. Mahmoud ${ }^{2}$, Sara Elsayed Ahmed ${ }^{\mathbf{1}}$ \\ 1. Forensic Medicine and Clinical ToxicologyDepartment, \\ 2. Pathology Department, \\ Faculty of Medicine, SohagUniversity.Sohag, Egypt
}

\section{INTRODUCTION}

Paracetamol is one of the most commonly used antipyretic and analgesic drug in the world, which has no adverse effect when used at the therapeutic dose (Kanno et al., 2006).It is available in more than 200 over the counter (OTC) and prescription medications, either singly or combined with other drugs (Patrick andEugene, 2007).

Paracetamol is associated with both intentional and unintentional poisoning (Bateman et al., 2014). Overdose of paracetamol can occur at any age. A therapeutic misadventure typically occurs in children younger than 1 year, when their caregivers give incorrect doses of a medication containing paracetamol. Accidental poisoning can occur in toddlers and young children with unsupervised access to medications. Older patients (eg, teenagers and adults) may use it intentional for suicide (Roberts, 2007).

\section{Chemistry of paracetamol}

Chemical name of paracetamol is $\mathrm{N}$ acetyl-p-aminophenol (APAP) which is a derivative of $p$-aminophenol that corresponds to the active principle metabolite phenacetin(swierkosz et al., 2002).

\section{Pharmacokinetics of paracetamol}

\section{A- Absorption:}

Paracetamol has a pKa of 9.5, and, in the alkaline medium of duodenum, is absorbed primarily by passive nonionic diffusion (McGill and Jaeschke, 2013).

b- Distribution:
The binding of paracetamol to plasma proteins is low $(10-25 \%)$, while it is

widely distributed, with a volume of distribution of $0.8-1 \quad 1 / \mathrm{kg}$ (Prescott, 2001).

Paracetamol has the ability to penetrate into the cerebrospinal fluid (CSF). It is also able to penetrate the placenta and is excreted in breast milk at low levels (Kumpulainenet al., 2007).

\section{c- Metabolism and elimination:}

In adults, paracetamol is metabolized mainly in the liver by glucuronidation (50-60\%), sulfation (25-30\%), and oxidation $\quad(<10 \%)$ Additionally, hydroxylation to form 3hydroxyparacetamol and methoxylation to form 3- methoxyparacetamol, along with excretion of free or unconjugated paracetamol in the urine, represent minor clearance pathways (McGill and Jaeschke, 2013).

All of the metabolites are excreted in the urine in a dose-dependent manner, with more than $90 \%$ of an administered dose excreted within $24 \mathrm{~h}$ (Ji et al., 2012).

Oxidation of paracetamol occurs via a CYP450-dependent, mixed-function oxidase enzyme pathway to form $\mathrm{N}$ acetyl-p-benzo-quinone imine (NAPQI). NAPQI is conjugated with intracellular glutathione to 3glutathione-S-yl-paracetamol (Gelotte et al., 2007).

\section{Administration}

Maximum paracetamol therapeutic dosages:The maximum daily adult dose 
of paracetamol is $4 \mathrm{~g}$, with a recommended dosage of $500 \mathrm{mg}$ every 4-6 hours.For children, the maximum daily dose is $75 \mathrm{mg} / \mathrm{kg}$, with a recommended dosage of $10-15 \mathrm{mg} / \mathrm{kg}$ every 4-6 hours as needed (Stockler et al., 2004).

Toxic paracetamol dosages: In adults, an acute ingestion of more than 150 $\mathrm{mg} / \mathrm{kg}$ or $12 \mathrm{~g}$ of paracetamol is considered a toxic dose and poses a high risk of liver damage. For children, a minimal, single paracetamol dose of $120-150 \mathrm{mg} / \mathrm{kg}$ may be associated with hepatotoxicity (Hodgman and Garrard, 2012)

\section{Mechanism of action}

a- At therapeutic dose:

It has been assumed that paracetamol mainly acts through the cyclooxygenase (COX) pathway. Its action appears to be mostly central; it readily passes the blood-brain barrier (Courade et al., 2001) and inhibits prostaglandin synthesis in the brain (Anderson, 2008).

The inhibition of the prostaglandin synthesis in the brain leads to temperature reduction probably modifying hypothalamic temperature set-point (Anderson, 2008).

\section{b- At toxic dose:}

The toxicity of paracetamol is closely linked to its metabolism. With therapeutic dosing, paracetamol is predominantly metabolized by glucuronidation and sulfation. Approximately $5 \%$ to $10 \%$ of the drug is oxidized by $\mathrm{CYP}_{450}$-dependent pathways to NAPQI. NAPQI is detoxified by glutathione and eliminated in the urine or bile (Yuan and Kaplowitz, 2013).

The NAPQI that is not detoxified may bind cysteine groups on proteins forming paracetamol-protein adducts in the liver. High levels of adducts correspond to liver toxicity in patients with paracetamol related acute liver failure (James et al., 2013).
Probably the NAPQI causes damage through binding mitochondrial proteins. This binding leads to decreased mitochondrial respiration, increased oxidative stress, and then to hepatic cellular necrosis (McGill and Jaeschke, 2013).

The kidney is the second target organ of paracetamol toxicity (Chen et al., 2015). Renal dysfunction after acute paracetamol overdose is the result of the local formation of NAPQI, which causes tubular necrosis(McGill and McGill, 2018).

\section{Toxicity ofparacetamol}

Paracetamol poisoning can be described in four sequential phases: preclinical toxic effects (phase one), hepatic injury (phase two), hepatic failure (phase three), and recovery, phase four (Heard, 2008).

i-The first phase occur a few hours after ingestion of a toxic dose, and lasts 12 to 24 hours. It consists of anorexia, nausea, vomiting, malaise, and diaphoresis, which may provoke administration of additional doses of paracetamol(Schilling et al., 2010).

ii-In the second phase, occurring up to 24 to 48 hours after ingestion, the first phase signs resolve and are replaced by right upper quadrant pain or tenderness, liver enlargement, and oliguria in some patients. Bilirubin, hepatic enzyme levels and the prothrombin time increase (Chun et al., 2009).

iii-In the third phase, usually 3 to 5 days into the course, anorexia, nausea, vomiting, and malaise reappear, along with signs of hepatic failure, including jaundice, hypoglycemia, coagulopathy, and encephalopathy. Renal failure and cardiomyopathy may also develop. Death may occur as a consequence of complications associated with hepatic failure, including multi-organ system failure, and cerebral edema (Larson, 2007).

iv-The fourth phase is associated with recovery or progression to death from 
SOHAG MEDICAL JOURNAL

complete liver failure. Approximately $70 \%$ of patients who enter phase four recover completely, while $1 \%$ to $2 \%$ of patients develop fatal hepatic failure. Severe, untreated paracetamoltoxicity will result in death within 4 to 18 days after ingestion (Chun et al., 2009).

Diagnosis of paracetamol toxicity:

1- Clinical assessment.

2- Lab:

a) The serum paracetamol concentration:

Paracetamol concentration in venous blood should be measured between 4 and 16 hours after ingestion of a single dose(Rumack, 2002). After a single ingestion, $N$-acetyl cysteine (NAC) therapy is guided by the serum APAP concentration. An APAP level 4 hours post ingestion of greater than 150 $\mathrm{mcg} / \mathrm{mL} \quad(>993 \mu \mathrm{mol} / \mathrm{L})$ reflects possible toxicity (Pakravan et al., 2009)

b) Liver function tests (LFTs).

Aspartate aminotransferase (AST) and alanine aminotransferase (ALT) concentrations begin to rise within 24 hours after an acute ingestion and peak at about 72 hours. In severe overdose, transaminase elevation can be detected as early as 12-16 hours post-ingestion (Farrell and Defendi, 2018). Toxicity is defined as serum AST or ALT concentrations greater than $1000 \mathrm{IU} / \mathrm{L}$. A rapid progression of transaminase values to $3000 \mathrm{IU} / \mathrm{L}$ or greater reflects severe hepatotoxicity (Green et al., 2010).

\section{c) Renal function tests}

Blood urea nitrogen [BUN], and creatinine concentrations can reveal evidence of co-existing renal failure and hepato-renal syndrome (Zyoud et al., 2011).

d) Arterial blood gas and serum lactate concentrations.

A pH of less than 7.3 or a lactate concentration greater than 3.5 after fluid resuscitation is laboratory
Review on Chemistry, Pharmacology Sara Elsayed Ahmed.et al

indicators predictive of mortality (Bernal et al., 2002).

e) Anion Gap

A high anion gap may be found in clinically ill patients who present soon after paracetamol ingestion; the etiology is hypothesized to be an elevated serum lactate concentration (Ferner et al., 2011).

f) NAPQI-Protein Adducts

Serum concentrations of NAPQIprotein adduct have been measured as evidence of paracetamol-induced hepatotoxicity.The peak serum concentrations of NAPQI adducts correlate with peak AST and ALT concentrations, and they may be diagnostic of APAP-induced hepatotoxicity in late-presenting patients with acute liver failure of unknown etiology (James et al.,2008).

\section{Rumack-Matthew Nomogram}

The Rumack-Matthew nomogram is used to interpret serum paracetamol concentrations in relation to time since ingestion, in order to assess potential hepatotoxicity(Bateman, 2015).

The nomogram predicts potential toxicity beginning at 4 hours after ingestion up to 24 hours after ingestion. Values obtained earlier than four hours cannot be interpreted because absorption is not yet complete. Values taken after 18 hours may be high because of acute liver injury that delays paracetamol metabolism. Concentrations measured 4-18 hours post-ingestion are most reliable (Rumack, 2002).

The upper line of the nomogram is the "probable" line, also known as the Rumack-Matthew line. It includes a paracetamol level of $200 \mu \mathrm{g} / \mathrm{mL}$ at 4 hours and $25 \mu \mathrm{g} / \mathrm{mL}$ at 16 hours after acute ingestion. About $60 \%$ of patients with values above this line develop hepatotoxicity (McGovern et al., 2015). The lower line on the nomogram is the "possible" line. The possible line, 
SOHAG MEDICAL JOURNAL

Vol. 23 No.2 Apr 2019
Review on Chemistry, Pharmacology Sara Elsayed Ahmed.et al also known as the "treatment" line, incorporates a $25 \%$ margin of error in measurement variations or uncertainty regarding the time of ingestion (Buehler and Curry, 2005).

The nomogram cannot be used if the patient presents more than 24 hours after ingestion or has a history of multiple paracetamol ingestions (Dart et al., 2006).

\section{I.7.Treatment:}

Supportive care is essential in paracetamol toxicity. Immediate assessment of the patient's airway, breathing, and hemodynamic status is critical, while considering and initiating treatment for suspected paracetamol overdose (Farrell and Defendi, 2018).

Administer activated charcoal (AC) if the patient has a stable mental and clinical status, patent airway, and presents to the emergency department within 1 hour of ingestion (Chyka et al., 2005).

Measure a 4-hour serum paracetamol concentration to assess the potential risk for hepatotoxicity, using the Rumack-Matthew nomogram. Patients with paracetamol concentrations below the "possible" line for hepatotoxicity on the RumackMatthew nomogram may be discharged home after they are medically cleared (Farrell and Defendi, 2018).

Admit patients with paracetamol concentrations above the "possible" line on the Rumack-Matthew nomogram for treatment with $\mathrm{N}$-acetyl cysteine (NAC).Treat patients with evidence of hepatic failure, metabolic acidosis, coagulopathy, and/or encephalopathy in an intensive care unit (ICU) (Bernal and Wendon, 2003).

The management of paracetamol toxicity focuses on prevention of hepatotoxicity by treatment with the antidote N-acetylcysteine (NAC) (Daly et al., 2008). Early administration of NAC after suspected paracetamol overdose is most essential.NAC is nearly $100 \%$ hepatoprotective when it is given within 8 hours after acute paracetamol ingestion but may still be of value up to 48 hours after ingestion (Whyteet al., 2007)

The primary mechanism of action of NAC is provision of cysteine which is a precursor of glutathione, it increases the concentration of glutathione available for the conjugation of NAPQI (Kozer and Koren, 2001).

* Criteria for liver transplantation include the following (Dargan and Jones, 2002):

- $\quad$ Metabolic acidosis ( $\mathrm{PH}<7.3$ ), unresponsive to resuscitation

- Renal failure (creatinine>300 $\mu \mathrm{mol} / \mathrm{L})$

- Coagulopathy (PT > 100 second, INR > 6,5)

- $\quad$ Encephalopathy (grade III, IV).

\section{Summary and conclusion}

Paractamolis one of the most widely used analgesic and antipyretic. It is considered safe at therapeutic dose. However, large dose can affect liver as well as kidney function. NAC is the specific antidote in paracetamol toxicity.

\section{References}

1. Anderson, B.J. (2008): Paracetamol (Acetaminophen): mechanisms of action. Paediatr. Anaesth., 18:p.915921.

2. Bateman, D. N. (2015):Paracetamol poisoning: beyond the nomogram. Br. J. Clin. Pharmacol., 80(1): p. 45-50.

3. Bateman, D.N.; Carroll, R.; Pettie, J.; Yamamoto, T.; Elamin, M.E. and Peart, L.(2014): Effect of the UK's revised paracetamol poisoning management guidelines on admissions, adverse reactions and costs of treatment. Br. J. Clin. Pharmacol., 78:p. 610-618.

4. Bernal, W. and Wendon, J. (2003): More on serum phosphate and prognosis of acute liver failure. Hepatology, 38:p. 533-534. 
SOHAG MEDICAL JOURNAL

Vol. 23 No.2 Apr 2019

5. Bernal, W.; Donaldson, N.; Wyncoll, D. and Wendon, J. (2002): Blood lactate as an early predictor of outcome in paracetamol-induced acute liver failure: a cohort study. Lancet, 359(9306): p.558-563.

6. Buehler, M.C. and Curry, S.C. (2005): False positive acetaminophen levels associated with hyperbilirubinemia. Clin. Toxicol.,43: p.167-170.

7. Chen, Y.G.; Lin, C.L.; Dai, M.S.; Chang, P.Y.; Chen, J.H.; Huang, T.C.; Wu, Y.Y. and Kao, C.H.(2015): Risk of acute kidney injury and long-term outcome in patients with acetaminophen intoxication: A nationwide populationbased retrospective cohort study. Medicine, 94(46):p. 2040-2046.

8. Chun, L.J.; Tong, M.J.; Busuttil, R.W.and Hiatt, J.R. (2009): Acetaminophen hepatotoxicity and acute liver failure. J. Clin. Gastroenterol., 43:p.342-349.

9. Chyka, P.A.; Seger, D.; Krenzelok, E.P. and Vale, J.A. (2005): Position paper: $\quad$ Single-dose activated charcoal. Clin.Toxicol., 43(2):p. 61-87.

10.Courade ,J.P.; Martin, K.; Besse, D.; Delchambre, C.; Hanoun, N.; Hamon, M.; Eschalier, A.; Caussade, F. and Cloarec, A. (2001) :Acetaminophen distribution in the rat central nervous system. Life Sci. 69:p. 1455-1464.

11.Daly, F.F.; O'Malley, G.F.; Heard, K.; Bogdan, G.M. and Dart, R.C (2004): Prospective evaluation of repeated supratherapeutic acetaminophen (paracetamol) ingestion. Ann. Emerg. Med., 44:p. 393-398.

12.Dargan, P.I. and Jones, A.L. (2002): Acetaminophen poisoning: an update for the intensivist. Crit. Care, (2):p.108-110.

13.Dart, R.C.; Erdman, A.R.; Olson, K.R.; Manoguerra, A.S.; Chyka, P.A.; Caravati, E.M.; Wax, P.M.; Keyes, D.C.; Woolf, A.D.; Scharman, E.J.; Booze, L.L and Troutman, W.G. (2006): Acetaminophen poisoning: an evidence-based consensus guideline for out-of-hospital management. Clin.Tox., 44:p.1-18.

14.Farrell, S.E. and Defendi, G.L. (2018): Acetaminophen toxicity treatment \&
Review on Chemistry, Pharmacology Sara Elsayed Ahmed.et al

management.

Available

at

https://emedicine.medscape.com/article/ 820200-overview.

15.Ferner, R.E.; Dear, J.W. and Bateman, D.N. (2011): Management of paracetamol poisoning. B.M.J., 342:p.2218-2227.

16.Gelotte, C.K.; Auiler, J.F.; Lynch, J.M.; Temple, A.R. and Slattery, J.T. (2007): Disposition of acetaminophen at 4,6 , and $8 \mathrm{~g}$ /day for 3 days in healthy young adults. Clin.Pharmacol.Ther., 81(6):p. 840-848.

17.Green, T.J.; Sivilotti, M.L.; Langmann, C.; Yarema, M.; Juurlink, D.; Burns, M.J. and Johnson, D.W. (2010): When do the aminotransferases rise after acute acetaminophen overdose? Clin.Toxicol., 48:p. 787-792.

18.Heard, K.J. (2008): Acetylcysteine for acetaminophen poisoning. N. Engl. J. Med., 359: p. 285-292.

19.Hodgman, M.J. and Garrard, A.R. (2012): A review of acetaminophen poisoning. Crit.CareClin., 28: p.499516.

20.Jaeschke, H.; Williams, C.D.; Ramachandran, A. and Bajt, M.L. (2012): Acetaminophen hepatotoxicity and repair: the role of sterile inflammation and innate immunity. Liver Int., 32:p. 8-20.

21.James, L.P.; Capparelli, E.V.; Simpson, P.M.; Letzig, L.; Roberts, D.; Hinson, J.A.; Kearns, G.L.; Blumer, J.L. and Sullivan, J.E. (2008): Acetaminophen-associated hepatic injury: evaluation of acetaminophen protein adducts in children and adolescents with acetaminophen overdose. Clin. Pharmacol.Ther., 84(6): p. $684-690$

22.James, L.P.; Chiew, A.; AbdelRahman, S.M.; Letzig, L.; Graudins, A.; Day, P. and Roberts, D. (2013): Acetaminophen protein adduct formation following low-dose acetaminophen exposure: comparison of immediate-release vs extended-release formulations. Eur. J. Clin. Pharmacol., 69:p.851-857.

23.Ji, P.; Wang, Y.; Li, Z.; Doddapaneni, S.; Hertz, S.; Furness, S. and Sahajwalla, C.G. (2012): Regulatory review of acetaminophen clinical 
pharmacology in young pediatric patients. J. Pharm. Sci., 101:p.43834389.

24.Kanno, S.; Tomizawa, A.; Hiura, T.; Osanai, Y.; Kakuta, M.; Kitajima, Y.; Koiwai, K.; Ohtake, T.; Ujibe, M. and Ishikawa, M. (2006): Melatonin protects on toxicity by acetaminophen

25.Kozer, E. and Koren, G. (2001): Management of paracetamol overdose: current controversies. Drug Safety, 24:p.503-512.

26.Kumpulainen, E.; Kokki, H.; Halonen, T.; Heikkinen, M.; Savolainen, J. and Laisalmi, M. (2007):Paracetamol (acetaminophen) penetrates readily into the cerebrospinal fluid of children after intravenous administration. Pediatrics, 119:p. 766-771.

27.Larson, A.M. (2007): Acetaminophen hepatotoxicity. Clin.Liver Dis.,11: p.525-548.

28.McGill, M.R. and Jaeschke, H. (2013): Metabolism and disposition of acetaminophen: recent advances in relation to hepatotoxicity and diagnosis. Pharm Res., 30:p.2174-2187.

29.McGill, S.K. and McGill, M.R. (2018): Extrahepatic toxicity of acetaminophen: critical evaluation of the evidence and proposed mechanisms. J. Clin. Transl. Res., 3(3):p. 5-31.

30.McGovern, A.J.; Vitkovitsky, I.V.; Jones, D.L. and Mullins, M.E. (2015): Can AST/ALT ratio indicates recovery after acute paracetamol poisoning? Clin. Toxicol., 53:p.164-167.

31.Michael, J.; Hodgman, M.D. and Alexander R. (2012): A review of acetaminophen Crit.CareClin., 28:p. 499-516.

32.Pakravan, N.; Simpson, K.; Waring, W.S.; Bates, C.M. and Bateman, D.N. (2009): Renal injury at first presentation as a predictor for poor outcome in severe paracetamol poisoning referred to a liver transplant unit. Eur.J.Clin. Pharmacol., 65: p.163-168.

33.Patrick, J. A. and Eugene, R. S. (2007): Acetaminophen safety and hepatotoxicity - where do we go from here. Expert Opinion on Drug Safety journal, 6:p.341:355.

34. Prescott, L.F. (2001): Paracetamol (acetaminophen): a critical bibliographic review, $2^{\text {nd }}$ ed. Taylor \& Francis, London:p.1001-1100.

35.Roberts, E.A. (2007): Drug induced liver disease. In: Suchy, F.J.; Sokol, R.J. and Balistreri, W.F.(eds.): Liver disease in children. $3^{\text {rd }}$ ed. Cambridge university press, USA:p. 478-512.

36.Rumack, B.H. (2002): Acetaminiphen hepatotoxicity: the first 35 years. J.Toxicol.Clin. Toxicol., 40:p.320.

37.Schilling, A.; Corey, R.; Leonard, M. andEghtesad, $\quad B . \quad$ (2010): Acetaminophen: old drug, new warnings. Cleve. Clin. J. Med., 77(1): p.19-27.

38.Stockler, M.; Vardy, J.; Pillai, A. and Warr, D. (2004): Acetaminophen (paracetamol) improves pain and wellbeing in people with advanced cancer already receiving a strong opioid regimen: a randomized, double-blind, placebo-controlled cross-over trial. J. Clin. Oncol., 22:p. 3389-3394.

39.Swierkosz, T.A.; Jordan, L.; Mcbride, M.; Mcgough, K.; Devlin,J. and Botting, R.M. (2002):Actions of paracetamol on cyclooxygenases in tissue and cell homogenates of mouse and rabbit.Med. Sci. Monit., 8(12):p.496-503.

40. Whyte, I.M.; Francis, B. and Dawson, A.H. (2007): Safety and efficacy of intravenous $\mathrm{N}$-acetylcysteine for acetaminophen overdose: analysis of the Hunter Area Toxicology Service (HATS) database. Curr.Med. Res.Opin. 23(10):p.2359-2368

41.Yuan, L. and Kaplowitz, N. (2013): Mechanisms of drug-induced liver injury. Clin.Liver Dis., 17:p. 507-518.

42.Zyoud, S.H.; Awang, R.; Sulaiman, S.A. and Al-Jabi, S.W. (2011): Impact of serum acetaminophen concentration on changes in serum potassium, creatinine and urea concentrations among patients with acetaminophen overdose. Pharmacoepidemiol. Drug Saf., 20(2):p. 203-208. 